Special

\section{Eommunications}

Submitted: 28 Sept 2020

Accepted: 5 Oct 2020

Online: 29 Dec 2020

\title{
Neurological Examination Techniques of Speech in Bahasa Malaysia for Adults: Simple Approach Practiced in Hospital Universiti Sains Malaysia
}

\author{
Abdul Haleem Noorsham ${ }^{1,4}$, Mohamad Muhaimin Abdullah ${ }^{1,5}$, \\ Sanihah Abdul Halım ${ }^{2,3,6}$, Abdul Rahman Izaini GHAN1 ${ }^{1,2,3}$, Zamzuri \\ IDRIS ${ }^{1,2,3}$, Jafri Malin ABDULLAH ${ }^{1,2,3}$ \\ 1 Department of Neurosciences, School of Medical Sciences, Universiti Sains \\ Malaysia, Kelantan, Malaysia \\ 2 Department of Neurosciences, Hospital Universiti Sains Malaysia, Universiti \\ Sains Malaysia, Kelantan, Malaysia \\ 3 Brain and Behaviour Cluster, School of Medical Sciences, Universiti Sains \\ Malaysia, Kelantan, Malaysia \\ 4 Department of Neurosurgery, Hospital Sultanah Nur Zahirah, Terengganu, \\ Malaysia \\ 5 Department of Neurosurgery, Hospital Sultanah Bahiyah, Kedah, Malaysia \\ 6 Neurology Unit, Department of Internal Medicine, School of Medical Sciences, \\ Universiti Sains Malaysia, Kelantan, Malaysia
}

To cite this article: Noorsham AH, Abdullah MM, Abdul Halim S, Ghani ARI, Idris Z, Abdullah JM. Neurological examination techniques of speech in Bahasa Malaysia for adults: simple approach practiced in Hospital Universiti Sains Malaysia. Malays J Med Sci. 2020;27(6):148-182. https://doi.org/10.21315/mjms2020.27.6.14

To link to this article: https://doi.org/10.21315/mjms2020.27.6.14

\section{Abstract}

There are four classification levels for speech disorders namely dysphonia, dysarthria, dysprosody and dysphasia. In general, speech examination mainly focuses on three main components that are spontaneous speech, auditory comprehension, and oral motor examination. Quick bedside assessment on speech in Bahasa Malaysia is essential to assist the speech language therapist (SLT) and other physicians to determine the disorders. Speech therapy is also essential in monitoring and continuous assessment for patients with speech and language disorders such as dysphasia and dysarthria. Speech clinicians in Hospital Universiti Sains Malaysia (HUSM) have been adapting two most widely used batteries of speech assessment tools namely Western aphasia battery-revised (WAB-R) by Andrew Kertesz and Boston diagnostic aphasia examination (BDAE). These tools have been modified into simple and validated speech assessments in Bahasa Malaysia. This video manuscript will demonstrate the use of both tools in performing bedside speech assessment for patients with speech disorders. The Bahasa Malaysia speech examination should not be difficult when WAB-R and BDAE speech assessment tools are applied. The aim of this simple approach using the adapted version of BDAE and WAB-R is to assist the clinician to achieve quick and accurate diagnosis with a validated scoring system.

Keywords: speech disorders, speech examination, dysphasia, dysarthria, Broca's dysphasia, Wernicke's dysphasia, Boston diagnostic aphasia examination, Western aphasia battery-revised, Bahasa Malaysia 


\section{Introduction}

There are 32.7 million people in Malaysia with diverse cultures and sharing different beliefs, customs, values, religions and languages (estimated: 69.1\% Malay, 23.0\% Chinese, 6.9\% Indians and $1 \%$ others) (1). A state in East Malaysia, Kelantan, consists of approximately 1.8 million Malay ethnicities (1) who speaks Malay dialect (2). The official language of Malaysia is the Malay language (Bahasa Melayu or Bahasa Malaysia) whereas English serves as the second language. A communicative speech consists of words arranged according to the rules of grammar and syntax and invested with prosody.

Speech disorders can be classified into four levels according to the site of lesions. Lesion at the lowest level is known as dysphonia due to the disturbance in the production of sounds in the larynx. Dysarthria is defined as a disorder in articulating speech sounds, which is due to the second lowest lesion. The next level of lesion is dysprosodies consisting of scanning speech (cerebellar), plateau speech (basal motor nuclei/ Parkinsonian), and stuttering, cluttering and absence of emotional inflections (cerebral). The highest level of lesion is known as dysphasia that is defined as the disturbance in the understanding or expression of words as symbols for communication (3). The two most common types of dysphasia are expressive and receptive dysphasia. Expressive dysphasia or known as Broca's aphasia is the non-fluent type of aphasia whereby the patient speaks telegraphically, sparsely, and slowly. Furthermore, receptive aphasia is known as Wernicke aphasia or fluent aphasia whereby a lesion happened in the Wernicke area of the brain that is responsible for comprehension of spoken words or written words (3).

Malaysia is known as multi-lingual country hence, speech examination among Malaysians is a huge challenge. The speech language therapist (SLT) in Hospital Universiti Sains Malaysia (HUSM) has been using two modified diagnostic aphasia batteries known as the Boston diagnostic aphasia examination (BDAE) (Appendix 1) (4) and Western aphasia battery-revised (WAB-R) by Andrew Kertesz (Appendix 2) (5). These tools have been used to perform a neurological examination of speech in HUSM among the Malay language speakers in Kelantan. BDAE and WAB-R are the best batteries to achieve an accurate diagnosis of speech disorders in adults. These batteries have been carefully adapted and translated into Bahasa Malaysia for the ease of communication and quick bedside assessment.

The goals for the examination are to determine the types of speech disorders, particularly expressive or receptive dysphasia, dysarthria, disorders in reading and writing or other oral motor disorders. The adapted assessment tools in general focus on three main components of speech examinations namely spontaneous speech, auditory comprehension and oral motor examinations. Reading and writing are included under the linguistic component, which is an extension from the three main core areas. The examinations scores are recorded at the end of the assessment and repeated within a certain period of time. Any improvement or deterioration from the first assessment can be monitored by per cases basis.

\section{Methods}

In general, the goal of speech examination in Bahasa Malaysia is to classify speech disorders into the types of aphasia namely expressive or receptive, dysarthria or other oral motor discrepancies. This can be achieved by focusing on the three main components of speech assessment including spontaneous speech, auditory comprehension and oral motor examination that includes repetition and naming (3). The fourth component, which is linguistic that includes extensive reading and writing examination, is tested thoroughly in a clinical setting (3). For practical purposes, the video of speech examination in Bahasa Malaysia can be viewed together with this article.

The speech examination performed at the bedside or at the clinic is performed using the adapted version of BDAE and WAB-R. Both batteries have been translated into Bahasa Malaysia in order for the SLT in HUSM to perform a better assessment. These two batteries are being used worldwide, adapted to various languages and not limited for diagnostic purposes, but also evaluation of language functionality and treatment designed for patients with aphasia $(6,7)$. Many groups have used these batteries that have been translated into Bahasa Malaysia in language assessments and treatment designs $(8,9,10,11,12,13,14)$. 


\section{Speech Assessment Typical Components}

\section{Case History}

Case history consists of a collection of information about speech difficulties particularly in the areas of language processes. These include difficulty in talking, hearing, vision, swallowing and other important medical conditions that may be related to the speech complaints. The medication history is also important especially the side effects of certain medications. Other histories include family, education level and patient's language proficiency in all language modalities. Patient's communication needs, as well as the family's expectation for therapy, is vital during case history session.

\section{Spontaneous Speech Examination}

The aims of spontaneous speech examination at the bedside are essential to evaluate the number of words spoken, the content and the associations of the sentences produced by the patient. These are essential for the physicians to determine the adequacy of response from the patient. Furthermore, another common method to initiate a response from the patient during spontaneous speech session is to ask the patient to tell a story or describing a picture to the examiner. This will aid the examiner to evaluate the types of conversation produced by the patient. The response was scored according to the contents of the conversation as seen in (Appendix 1) and (Appendix 2).

This first assessment plays important role in determining the fluency of patient's speech to direct the assessment pathway in further evaluating the speech disorders at the end of the assessment. Patient that is non-fluent in speech but has an appropriate content will be directed to the auditory speech comprehension in view that the patient may have a lesion at the Broca's region (speech production).

\section{Auditory Comprehension}

Comprehension test consists of word comprehension, commands and complex ideational material. The sentences are verbalised by the examiner and the patient has to pinpoint to one of four visual stimuli indicating the correct sentence. The patient also has to perform a spoken command in which the patient has to answer the questions correctly. Finally, a short story will be read to the patient and the patient needs to answer questions related to the story (Appendix 1) (Appendix 2). The aim of this test is to capture either the patient has impaired comprehension in understanding grammar and syntax, words in relation to other words or difficulty with semantics and understanding individual words.

\section{Oral Expression}

Oral expression assesses two major areas, which are repetition and naming. These two components are important to distinguish the patient either anomic or conductive aphasia whereby the lesion is at dominant parietal or arcuate fasciculus, respectively. The patient needs to recite sentences under automatised sequences, repeat single, sentences, naming objects and basic symbols as shown by the examiner (Appendix 1) (Appendix 2). The aim of oral motor expression is to determine any deficit in articulation that is responsive to certain muscles involved in producing speech.

\section{Reading}

Reading test is performed to test the patient's ability to comprehend written language symbols by reading. Written language is perceived by the visual system and the information conveyed to the perisylvian language centers. Patient is also asked to read basic symbol using visual cues and the patient has to choose appropriate words related to the pictures being shown and reading comprehension (Appendix 1) (Appendix 2). The inability of the patient to read (alexia) reflects a dysfunction to the language centers or interruptions of the connections with the visual system.

\section{Writing}

Patients who are aphasic in speech are also aphasic in writing, however, writing ability may be preserved in patients with dysarthria or verbal apraxia. The ability of the patients to perform mechanical writing is assessed before writing words, repeating the spoken objects and drawing the pictures shown by the examiner. The test was ended by requesting the patient to write a story based on a picture and the content is evaluated (Appendix 1) (Appendix 2). The areas of writing such as mechanical, grammar, syntax and contents are scored accordingly. 
Special Communications | Neurological examination of speech in Bahasa Malaysia

\section{Assessment Tools}

The accurate and quick diagnosis from bedside to full speech examination to determine the types of aphasia is important in confirming the localisation of cortical to oral motor lesions. This will assist the clinician in designing the best effective treatment program for the patients. At present, many assessment tools are available to perform speech examination, which can be divided into formal and informal (Table 1). This paper summarises the commonly used assessment tools by HUSM speech clinicians in clinic and bedside settings. The tools are divided to classification and non-classification test of aphasia (Table 1) (15). The classification test for aphasia that is commonly used and adapted to multi-languages are WAB-R and BDAE whereby the non-classification test for aphasia are Minnesota test for differential diagnosis of aphasia (MTDDA) (19), Porch index of communicative ability (PICA) (20), American speech and hearing association functional assessment of communication skills (ASHA FACS) (21), and communication abilities in daily living (C-ADL) (22). However, for formal screening language test, the Frenchay aphasia screening test (FAST) (18) and the language screening test (LAST) (16) has been validated to be used in emergency setting. The MTDDA and PICA tests are used for prognostic purpose whereby the ASHA FACS aims towards functional assessment on the effect of aphasia on the patient's daily activities (21). The most commonly used formal assessment tool by speech-language therapist in HUSM is the BDAE. This tool has been adapted into Bahasa Malaysia and has been used since 2012 (Appendix 1). The adaptation of these two batteries to Bahasa Malaysia reflects that Bahasa Malaysia is the main language while Malay dialect is spoken by the majority of Kelantanese people (2). The northeastern region of Peninsular Malaysia has the largest Malay language speakers due the location that is at Malaysia-Thailand border (23). Furthermore, the assessment tool is translated into Malay language since it is part of national education system and is also used for formal duty at school and working place (24). This adapted version has been used for many years in HUSM and its reliability and validity correspond to the original adaptation of BDAE, which has been used worldwide as aphasia test. The clinicians in HUSM also adapted the WAB-R, which is one of the popular aphasia tests used worldwide (Appendix 2).

Video on speech examination in Bahasa Malaysia accompanies this manuscript at https://youtu.be/uyVVn4X-cSo

Table 1. List of assessment tools for classification and non-classification test of aphasia

Formal assessments
Classification test
WAB - Western aphasia battery (5)
BDAE - Boston diagnostic aphasia examination (4)
ANELT - Amsterdam-Nijmegen everyday language test (17)
Formal screening tools
FAST - Frenchay aphasia screening test (18)
The language screening test (LAST) (16)
Non-classification test
MTDDA - Minnesota test for differential diagnosis of aphasia
(19)
PICA - Porch index of communicative ability (20)
American speech and hearing association functional
assessment of communication skills (ASHA FACS) (21)
Communication abilities in daily living (C-ADL) (22)




\section{Outcome of the Assessment}

Through the formal assessment using the adapted version, the examination of speech in Bahasa Malaysia aims to examine linguistic skills such as information content, fluency, auditory comprehension, repetition, naming and word finding, reading and writing as well as non-linguistic skills such as drawing, calculation, block design, and praxis of adults with aphasia. Both batteries have different scoring systems whereby the BDAE uses percentile rank scoring system (3) whereas WAB-R uses point scoring system (4). The outcome of both assessment tools is to achieve an accurate diagnosis for aphasia classification, to evaluate the severity of aphasia, and to determine the adult's language functionality with aphasia for rehabilitation and treatment programme.

\section{Conclusion and Future Studies Directions}

In this paper, the simple approach to examine Bahasa Malaysia speech using the adapted version of worldwide aphasia tests namely BDAE and WAB-R was described. These two batteries have been validated for reliability and validity to be used in many other languages apart from Bahasa Malaysia. The aims of this simple approach in examining speech in Malay speaking Malaysian population are to assist the speech clinicians and the non-speech clinicians to determine the types of aphasia in patients presented with acute setting or in the clinical setting.

\section{Acknowledgements}

None.

\section{Conflict of Interest}

None.

\section{Funds}

None.

\section{Authors' Contributions}

Conception and design: AHN, JMA

Critical revision of the article for important intellectual content: AHN, MMA, SAH, ARIG, ZZ, JMA

\section{Correspondence}

Dr Abdul Haleem Noorsham

MB BCh BAO (NUI)

Department of Neurosciences,

School of Medical Sciences, Universiti Sains

Malaysia,

16150 Kubang Kerian, Kelantan, Malaysia.

Tel: +609 7676300

Fax: +609 7673833

E-mail: abdulhaleemnoorsham7@student.usm. my.

\section{References}

1. Mahidin MU. Selected demographic indicators Malaysia, 2019 [Internet]. Department of Statistics Malaysia; 2019.

2. Collins J, Ahmad Z. The Malay language and ethnic identity in modern Malaysia. Akademika. 1999;55:133-148.

3. Biller J, Gruener G, Brazis PW. DeMyers's the neurologic examination: a programmed text. 7 th ed. USA: The McGraw-Hill Companies, Inc.; 2017.

4. Goodglass H, Kaplan E, Barresi B. Boston diagnostic aphasia examination. 2001. 3rd ed. Philadeplphia, PA: Lippincot. https://doi. org/10.1007/978-0-387-79948-3

5. Kertesz A. Western aphasia battery-revised (WAB-R). UK: Pearson Education Ltd. London; 2006.

6. Shewan CM, Kertesz A. Reliability and validity characteristics of the Western aphasia battery (WAB). $J$ Speech Disord. 1980;45(3):308. https://doi.org/10.1044/jshd.4503.308

7. Powel T. A reliability study of BDAE-3 discourse coding. Clinical Linguistic \& Phonetics. 2006;20(7-8):607-612. https://doi.org/ 10.1080/02699200500266679 
8. Aziz MA, Hassan M, Razak RA, Garraffa M. Syntactic abilities in Malay adult speakers with aphasia: a study on passive sentences and argument structures. Aphasiology. 2020;34(7):886-904. https://doi.org/10.1080/o 2687038.2020.1742283

9. Aziz MA, Hassan M, Razak R, Garraffa M. Targeting complex orthography in the treatment of a bilingual aphasia with acquired dysgraphia: the case of a Malay/English speaker with conduction aphasia. Behav. Sci. 2020;10(7):109. https://doi.org/10.339o/bs10070109

10. Aziz MA, Shahidi AH. Kemahiran berkomunikasi dalam kalangan penutur dewasa Melayu dengan afasia. Jurnal Melayu. 2017;16:318-322.

11. Aziz MA, Mukhtar F, Onwi N, Mahmud N. Demographic and clinical profiles of patients with aphasia in Malaysia: preliminary data. $J$ Rehabil Med Suppl. 2016;55:991.

12. Aziz MA, Abdul A, Razak A, Hamid B. Word retrieval deficits in Malay-speaking adults with non-fluent aphasia. Procedia Soc Behav Sci. 2013;94:69-70. https://doi.org/10.1016/j. sbspro.2013.09.031

13. Aziz MA, Razak R. Semantic feature analysis (SFA) in the treatment of naming deficits: evidence from a Malay speaker with nonfluent aphasia. In: Conference abstract: Academy of Aphasia 53rd Annual Meeting; 18 Oct-20 Oct 2015; Tucson, United State. Front Psychol; 2015. https://doi.org/10.3389/conf. fpsyg.2015.65.00052

14. Aziz MA, Shahidi A, Hamid Z. Imageability and familiarity effect on comprehension of nouns and verbs in Malay-speaking adults with aphasia. Conference abstract. Academy of Aphasia 55th Annual Meeting; 5 Nov-7 November 2017; Baltimore, United State. https://doi.org/10.3389/ conf.fnhum.2017.22300106

15. Crary MA, Wertz RT, Deal JL. Classifying aphasias: cluster analysis of Western aphasia battery and Boston diagnostic aphasia examination. Aphasiology.1992;6:29-36.

16. Flamand-Roze et al. Validation of a new language screening tool for patients with acute stroke. The language screening test (LAST). Stroke. 2011;42:1224-1229. https://doi.org/10.1161/ STROKEAHA.110.609503
17. L. Blomert M, Kean L, Koster CH, Schokker J. Amsterdam-Nijmegen everyday language test: construction, reliability and validity. Aphasiology. 1994;8(4):381-407. https://doi. org/10.1080/02687039408248666

18. Enderby PM, Wood VA, Wade DT, Hewer RL. The Frenchay aphasia screening test: a short, simple test for aphasia appropriate for non-specialists. International Journal of Rehabilitation Medicine. 1986;8(4):166-170. https://doi. org/10.3109/03790798709166209

19. Benveniste S. Differential diagnosis of aphasia with the Minnesota test. Arch Gen Psychiatry. 1966;14(2):224. https://doi.org/10.1001/ archpsyc.1966.01730080112019

20. Silverman F. The Porch index of communicative ability (PICA): a psychometric problem and its solution. J Speech Hear Disord. 1974;39(2):225226. https://doi.org/doi.org/10.1044/jshd. 3902.225

21. Frattali CM, Thompson CK, Holland AL, Wohl CB, Ferketic MM. The American SpeechLanguage-Hearing Association Functional Assessment of Communication Skills for Adults (ASHA FACS). Rockville, MD: ASHA; 1995.

22. Byeon H, Koh HW. The relationship between communication activities of daily living and quality of life among the elderly suffering from stroke. $J$ Phys Ther Sci. 2016;28(5):1450-1453. https://doi.org/10.1589/jpts.28.1450

23. Jaafar $M$, Mat $N$, Azlan $M$, Lateh $H$. The patterns of language choice at the border of Malaysia-Thailand. Indonesia Journal of Applied Linguistics. 2016;2(5):176. https://doi. org/10.17509/ijal.v5i2.1342

24. How S, Chan S, Abdullah A. Language vitality of Malaysia Languages and its relation to identity. Journal of Language Studies. 2015;15(2):119132. https://doi.org/10.17576/gema-2015-150208 


\section{Appendix 1: Adapted version of BDAE in Bahasa Malaysia}

SLT - BORANG PENILAIAN KECELARUAN BAHASA PEROLEHAN DEWASA (ADAPTASI BOSTON DIAGNOSTIC APHASIA EXAMINATION [BDAE]) UNIT PEMULIHAN PERTUTURAN-BAHASA

HOSPITAL

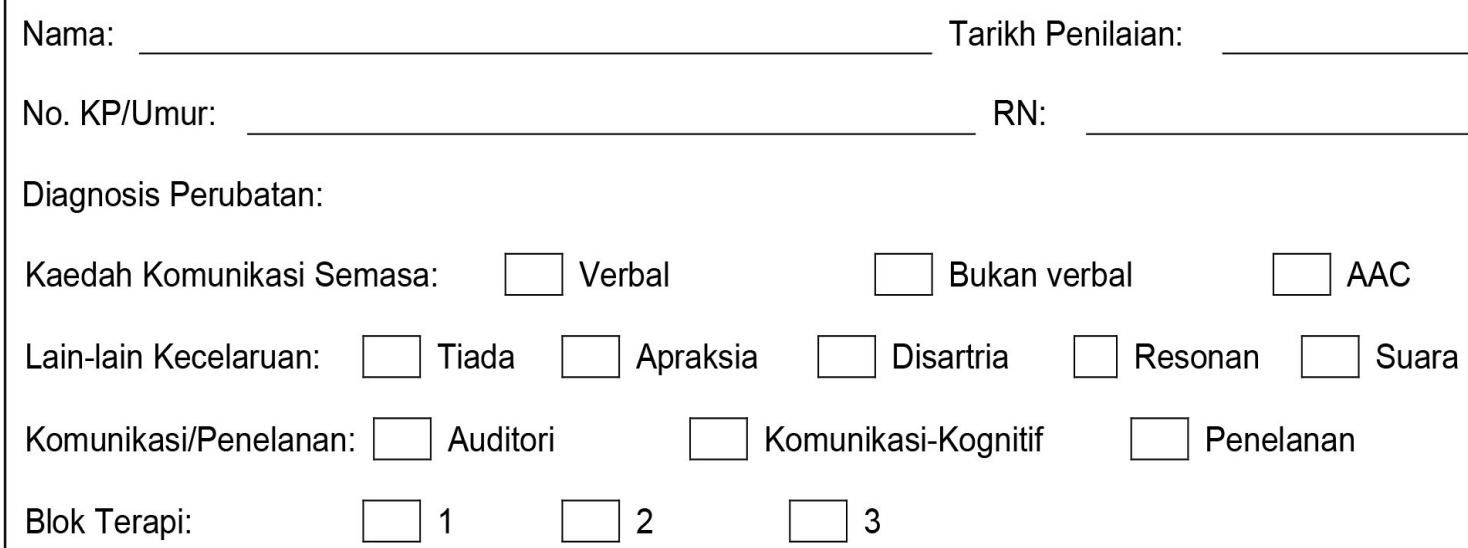

\section{PERBUALAN \& PERTUTURAN SPONTAN}

\section{A. Respon kepada Ucapan Sosial}

Arahan: Perbualan terbuka dengan pesakit untuk mendapatkan respon sebanyak yang mungkin. Tulis respon pesakit dan catatkan markah pada kotak di bawah

1. Apa khabar?

2. Apa nama penuh?

3. Pernah datang ke sini sebelum ini?

4. Suka makan apa?

5. Tinggal dekat mana?

Markah: 115 Lulus (markah: 15/15) 
Special Communications | Neurological examination of speech in Bahasa Malaysia

\section{B. Perbualan Terbuka \& Penerangan Gambar}

\section{i) Perbualan terbuka}

Arahan: Berbual dengan pesakit. Mulakan perbualan dengan topik yang biasa. Galakkan perbualan sekurang-kurangnya 3 minit dan cuba elakkan soalan dengan jawapan 'ya, tidak'. Tulis respon pesakit dan catatkan markah pada kotak di bawah.

1. Dulu kerja apa?

2. Ceritakan pada saya apa yang terjadi sehingga datang ke sini.

\section{ii) Penerangan gambar}

Arahan: Minta pesakit huraikan gambar. Tunjuk pada pesakit bahagian yang diabaikan dan minta pesakit huraikan. Rekod respon pesakit. Catatkan markah pada kotak di bawah

Tandakan (1) jika pesakit menunjukkan ciri-ciri pertuturan seperti di bawah:

\begin{tabular}{|c|l|l|}
\hline Bil & \multicolumn{1}{|c|}{ Ciri-ciri pertuturan dalam perbualan } & Respon \\
\hline 1 & Pertuturan lancar & \\
\hline 2 & Memberi respon yang bersesuaian & \\
\hline 3 & Mengekalkan topik perbualan & \\
\hline 4 & Menggunakan ayat & \\
\hline 5 & Menggunakan frasa & \\
\hline 6 & Menggunakan perkataan tunggal & \\
\hline 7 & Menggunakan struktur ayat yang bersesuaian & \\
\hline 8 & Tiada Parafasia & \\
\hline 9 & Tiada Circumlocution & \\
\hline 10 & Tiada verbal stereotype & \\
\hline 11 & Tiada perseveration & \\
\hline 12 & Tiada Anomia & \\
\hline 13 & Tiada Neologism & \\
\hline 14 & Tiada perkataan tidak bermakna (jargon) & \\
\hline 15 & Pemahaman auditori & \\
\hline
\end{tabular}

Skor: $/ 15$

Lulus (markah: 15/15) 


\section{PEMAHAMAN AUDITORI}

\section{A. Pemahaman Perkataan}

Arahan: Minta pesakit untuk menunjuk gambar yang disebut oleh terapis. Rekod respon dan catatkan markah pada kotak di bawah:

\begin{tabular}{|l|l|l|}
\hline Stimulus & $\begin{array}{c}\text { Lulus (respon }<10 \\
\text { saat) }\end{array}$ & Gagal \\
\hline 1. bahu & & \\
\hline 2. pipi & & \\
\hline 3. lilin & & \\
\hline 4. lembu & & \\
\hline 5. kacang & & \\
\hline 6. topi & & \\
\hline 7. bas & & \\
\hline 8. gergaji & & \\
\hline 9. semut & & \\
\hline 10. bunga raya & & \\
\hline 11. biru & & \\
\hline 12. coklat & & \\
\hline 13. T & & \\
\hline 14. N & & \\
\hline 15. 4 & & \\
\hline 16. 13 & & \\
\hline
\end{tabular}

Skor:

116

Lulus (markah: 16/16)

\section{B, Arahan}

Arahan: Baca arahan di bawah dan minta pesakit mengikut arahan yang di beri. Satu markah diberi bagi setiap arahan yang dibuat dengan tepat. Ulangan dibenarkan jika diminta tetapi keseluruhan arahan perlu diulang. Rekodkan respon dan catatkan markah pada kotak di bawah.

1. Pejam mata

2. Tunjuk meja dan kerusi

3. Tunjuk lampu dan pintu

4. Angkat tangan kanan dan geleng kepala

5. Sentuh setiap bahu 2 kali dengan 2 jari, dengan mata tertutup

Skor: 15

Lulus (markah: 5/5) 


\section{Menjawab soalan Ya/Tidak}

Arahan: Baca soalan di bawah dan minta pesakit member i respon 'ya / tidak'. Satu markah diberi bagi setiap reson tepat. Ulangan dibenarkan jika diminta, tetapi keseluruhan ayat perlu diulang. Rekod respon dan catatkan markah pada kotak di bawah.
1. Lembu boleh terbang?
2. Minyak larut dalam air?
3. 5 lebih besar dari 3 ?
4. Gula rasa manis?
5. Darah warna biru?

Skor: 15 Lulus (markah: 5/5)

\section{Memahami petikan}

Arahan : Bacakan satu cerita pendek dan tanya soalan di bawah selepas itu. Rekod respon dan catatkan markah pada kotak di bawah.

Ali terpaksa pergi ke Ipoh. Dia bercadang untuk menaiki keretapi. Isterinya menghantarnya ke stesen keretapi dengan kereta tetapi dalam perjalanan, tayar kereta mereka pancit. Walaubagaimanapun, mereka sempat tiba di stesen keretapi dan Ali pun sempat menaiki keretapi tersebut.

1. Ali tertinggal keretapi?

2. Ali pergi Ipoh ke?

3. Ali sempat tiba di stesen keretapi?

4. Ali balik dari Ipoh?

Skor: 14

Lulus (markah: 4/4)

Siti pergi ke pasar bersama ibu dan adik lelakinya. Mereka pergi dengan menaiki kereta. Dia membawa wang sebanyak RM50. Mereka membeli ayam, sayur kobis dan buah epal. Kemudian, mereka singgah makan tengahari di gerai Pak Mat. Mereka pulang ke rumah dan Siti memasak nasi ayam

1. Siti pergi mana?

2. Siti pergi dengan siapa?

3. Mereka beli apa?

4. Mereka makan tengahari kat mana?

5. Siti masak apa?

Skor: 15

Lulus (markah: 5/5) 


\section{EKSPRESI LISAN}

\section{A. Pertuturan Automatik}

Arahan: Beri bantuan bagi perkataan pertama jika perlu. Berikan bantuan selanjutnya jika perlu namun hentikan jika 4 siri gagal. Pemarkahan diberi bagi siri yang berturutan tanpa bantuan SLP. Rekodkan respon dan catatkan markah.

\begin{tabular}{|l|c|c|}
\hline & 1 markah & 2 markah \\
\hline 1.Hari dalam seminggu & $(4$ siri) & (Semua) \\
\hline 2.Bilang $1-20$ & $(8$ siri $)$ & (Semua) \\
\hline
\end{tabular}

\section{B. Pengulangan}

Arahan: Sebut stimulus di bawah dan minta pesakit mengulang kembali. Ulang perkataan/ayat sekali lagi jika diminta. Markah diberi jika respon difahami. Rekodkan kesalahan artikulasi dan catatkan markah pada kotak di bawah.

1. Bas

2. Kopi

3. Tembikai

4. Fosha

5. Tanpul

6. Dapaha

7. Pak Abu pulang ke rumah

8. Mak Tom masak kari ayam

Skor: 18

Lulus (markah: 8/8)

\section{Menamakan}

Arahan: Baca ujaran di bawah, minta pesakit menamakan objek/item yang berkaitan dengan maksud ujaran tadi. Rekodkan respon dan catat markah pada kotak di bawah.

1. Penamaan berespon

\begin{tabular}{|l|l|}
\hline \multicolumn{1}{|c|}{ Ayat } & Respon \\
\hline a. Kita duduk atas apa? & \\
\hline b. Rumput warna apa? & \\
\hline c. Gula rasa apa? & \\
\hline d. Tendang bola dengan apa ? & \\
\hline e. Potong buah guna apa? & \\
\hline
\end{tabular}

Skor:

15

Lulus (markah: 5/5) 
Special Communications | Neurological examination of speech in Bahasa Malaysia

2. Penamaan konfrontasi (Confrontation naming)

Arahan: Tunjukkan gambar, minta pesakit menamakan gambar yang ditunjuk tadi. Rekod respon dan catatkan.

\begin{tabular}{|c|l|c|}
\hline No & \multicolumn{1}{|c|}{$\begin{array}{c}\text { Stimulu } \\
\text { s }\end{array}$} & Respon \\
\hline 1 & Jam & \\
\hline 2 & Bas & \\
\hline 3 & Bola & \\
\hline 4 & Kasut & \\
\hline 5 & Cawan & \\
\hline 6 & Lembu & \\
\hline 7 & Bendera & \\
\hline 8 & Tembikai & \\
\hline 9 & Matahari & \\
\hline 10 & Helikopter & \\
\hline
\end{tabular}

Skor:

110

Lulus (markah: 10/10)

\section{MEMBACA}

\section{A. Mengenal pasti simbol asas}

1. Memadankan huruf dan skrip

$\begin{array}{llllll}\text { G } & - & \text { h } & \text { Q } & \text { G } & \text { S } \\ \text { F } & - & \text { f } & \text { T } & \text { S } & \text { p } \\ \text { Pop } & - & \text { BAN } & \text { TOP } & \text { Pop } & \text { dot } \\ \text { OAT } & - & \text { AM } & \text { la } & \text { Tin } & \text { oat }\end{array}$

2. Memadankan nombor (Jari kepada nombor)

$\begin{array}{llllll}5 & 6 & 4 & 5 & 3 & 2 \\ 4 & 5 & 1 & 7 & 4 & 6\end{array}$

3. Memadankan nombor (Nombor kepada titik)

$$
\begin{aligned}
& \begin{array}{lllll}
3 \ldots & 3 \ldots & 4 \ldots & 7 \ldots \ldots .5 \ldots .
\end{array} \\
& 7 \ldots \ldots .5 \ldots .4 \ldots . .6 \%
\end{aligned}
$$

Skor:

Skor:

14


B. Mengenal perkataan (padankan gambar perkataan)
1a. Jam
2a. jem
3a. bus
4a. ais
5a. beg
1b. Buku
$2 b$. baca
3b. surat
1c. Katil
2c. tidur
3c. katil
4b. bulu
5b. Biru
1d. Teropong
2d. basikal
3d. telekung
Tangan 5c. semut
4d. Helikopter 5d. Tembikai

Skor: $\_14$

\section{Membaca secara lisan}

Araha : Minta pesakit membaca perkataan satu persatu. Beri bantuan jika diperlukan. Markah tidak diberi pada respon dengan bantuan. Rekod respon dan catatkan markah.

\section{Membaca perkataan asas}

\begin{tabular}{|l|c|c|c|c|}
\hline & $\begin{array}{c}\text { 0-3 saat } \\
\text { (3 markah) }\end{array}$ & $\begin{array}{c}\text { 3-10 saat } \\
(2 \text { markah })\end{array}$ & $\begin{array}{c}\text { 10-30 saat } \\
\text { (1 markah) }\end{array}$ & $\begin{array}{c}\text { Gagal } \\
\text { (0 markah) }\end{array}$ \\
\hline Cas & & & & \\
\hline Sekat & & & & \\
\hline Hamper & & & & \\
\hline Papan & & & & \\
\hline Foto & & & & \\
\hline
\end{tabular}

Skor: 115

2. Membaca ayat dan memahami ayat yang dibaca

Arahan: Minta pesakit membaca dengan kuat. Markah diberi jika tiada kesalahan dilakukan. Rekod respon dan catatkan markah.

1. Hari yang bagus untuk ke pantai

2. Johan dan Mira menyediakan bekalan makanan tengah hari

3. Selepas memandu selama 45 minit, mereka tiba di pesisiran pantai

4. Apabila mereka habis berenang, mereka berasa amat lapar

5. Mujurlah mereka menjumpai gerai makanan yang mempunyai pelbagai pilihan makanan.

Skor:

Arahan: Terapis hanya boleh menunjuk pada pilihan jawapan dan soalan. Pesakit perlu memilih jawapan yang tepat sama ada dengan menunjuk, membaca atau kedua-duanya. Catatkan markah.

1. Cuaca pada hari itu

sejuk panas - rangup hujan

2. Mira dan Johan menaiki

keretapi bot kereta

3. Perjalanan itu mengambil masa selama setengah hari

5 minit

45 minit

kapalterbang

2jam

Skor: 
Special Communications | Neurological examination of speech in Bahasa Malaysia

\section{Pemahaman pembacaan}

Arahan: Terapis boleh membacakan soalan dan pilihan jawapan (model terlebih dahulu). Selepas itu, Pesakit perlu membacakan pilihan soalan dan pilihan jawapan (seperti yang dilakukan oleh terapis) tanpa bantuan. Catatkan markah.

1. Anjing boleh ...

Bercakap Menyalak Menyanyi Kucing

2. Encik Johan mencuci dan menggunting rambut. Dia seorang ....
Pencukur
Budak lelaki
Penjual daging
Penggunting rambut

3. Pembinaan sekolah dan jalanraya memerlukan wang dan kita bayar melalui...
Rumah
Negara
Cukai
Polis

4. Pada masa dahulu aluminium sangat mahal untuk diasingkan, Sekarang elektrik telah menyelesaikan masalah tersebut dan aluminium sudah menjadi ....

Sangat kukuh

Pelombong

Elektronik

Lebih murah

Skor:

\section{MENULIS}

\section{A. Penulisan Mekanikal}

Arahan: Minta pesakit melaksanakan 7 tugasan di bawah. Bagi pemarkahan 'well-formedness' terapis tidak perlu mengambilkira huruf atau nombor yang ditulis oleh pesakit itu sama ada betul atau salah. Rekod respon dan catatkan markah.

Well-formedness of letter Correctness of letter choice

: 2-all well formed, 1-partly malformed, 0-illegible : 3-no error, 2->half, 1-<half, $0-<2$ correct :-not impaired, 1-laborious, 0-failure of motor control

TUGASAN $\quad$ KOMEN

\begin{tabular}{|l|l|l|}
\hline BIL & \multicolumn{1}{|c|}{ TUGASAN } & KOMEN \\
\hline 1 & Tandatangan & \\
\hline 2 & Tulis nama & \\
\hline 3 & Dengar \& Eja huruf (T-G-R-S-B) & \\
\hline 4 & Tiru : 'HARAPKAN PAGAR, PAGAR MAKAN PADI' & \\
\hline 5 & Tiru singkatan nama (PM-YB-TV-UKM-KL) & \\
\hline 6 & Tulis nombor 1-20 & \\
\hline 7 & Dengar \& tulis nombor (2-12-9-11-6) & \\
\hline
\end{tabular}




\section{B. Kebolehan mengeja}

Arahan: Minta pesakit menulis perkataan yang disebut. Rekodkan respon dan catatkan markah.

1. Perbendaharaan kata primer
a. cat
b. lari
c. pergi
d. kucing

Skor:

2. Fonik biasa
a. jag
b. telefon
c. pemandu
d. tomato
e. pingpong

Skor: 15

\section{Menamakan Gambar/Objek Secara Bertulis}

Arahan: Minta pesakit menulis nama objek, gambar atau perbuatan yang ditunjukkan oleh pegawai. Catatkan markah

1. Objek

- pokok, sudu, bot, tali

Skor: 14

2. Perbuatan

- berenang, menyapu, tidur, sepak

Skor: 14

3. Haiwan

- lembu, tupai, ayam, harimau

Skor: 14

\section{Menulis Cerita}

Arahan: Tunjuk gambar 'cookie thief picture'. minta pesakit, menulis sebanyak mungkin ayat tentang gambar tersebut'. Jika pesakit tidak dapat melakukannya dengan mudah, tanya 5 soalan untuk membantu pesakit.

1. Apa kaitan orang-orang dalam gambar ini?

2. Apa yang berlaku di belakang wanita itu?

3. Mengapa budak perempuan itu melarang budak lelaki itu membuat bising.

4. Mengapa anda fikir budak lelaki itu mungkin akan tercedera?

5. Apa lagi perkara yang terjadi pada emak? 
Special Communications | Neurological examination of speech in Bahasa Malaysia

Pemarkahan: Markah diberikan berdasarkan 4 dimensi seperti di bawah. la dinilai berdasarkan kehadiran ciri-ciri yang disasarkan seperti 'Perempuan/emak itu, budak lelaki itu'. Penjelasan kualitatif seperti berikut.

\begin{tabular}{|c|c|c|c|}
\hline Mekanik & Akses tatabahasa bertulis & Sintaks & Kecukupan Isi \\
\hline $\begin{array}{l}\text { 2- cantik terbentuk } \\
1 \text { - boleh dibaca tapi } \\
\text { ada kecacatan } \\
\text { 0-kebanyakkannya } \\
\text { boleh dibaca }\end{array}$ & $\begin{array}{l}\text { 3-cukup } \\
\text { 2-beberapa perkara } \\
\text { penting hilang } \\
1 \text {-<dari } 8 \text { perkataan } \\
\text { penting }\end{array}$ & $\begin{array}{l}\text { 3-semua betul } \\
\text { 2-sedikit kecacatan } \\
\text { dalam struktur ayat } \\
\text { 1-kebanyakkannya } \\
\text { pengumpulan subklausa }\end{array}$ & $\begin{array}{l}\text { 3-cukup } \\
\text { 2-penting tapi } \\
\text { tak cukup } \\
\text { 1-maklumat } \\
\text { penting }\end{array}$ \\
\hline Maklumat & $0-<$ dari 2 perkataan penting & $\begin{array}{l}\text { 0-tiada pengumpulan } \\
\text { perkataan }\end{array}$ & $\begin{array}{l}\text { 0- tiada } \\
\text { penting }\end{array}$ \\
\hline Kualitatif: & & & \\
\hline $\begin{array}{l}\text { 1. Menulis perkataan } \\
\text { Berulang }\end{array}$ & $\begin{array}{l}\text { 1ajmuk yang tidak penting } \\
\text { kadang-kadang }\end{array}$ & tak pernah & \\
\hline $\begin{array}{l}\text { 2. Penggantian perke } \\
\text { Berulang }\end{array}$ & $\begin{array}{l}\text { lan tunggal } \\
\text { kadang-kadang }\end{array}$ & tak pernah & \\
\hline
\end{tabular}

KOMEN (Jika ada) :

\begin{tabular}{|c|c|l|}
\hline \multicolumn{2}{|c|}{ SESI } & \\
\hline \multirow{3}{*}{ PENILAIAN } & P1 & \\
\cline { 2 - 3 } & P2 & \\
\hline \multirow{4}{*}{$\begin{array}{c}\text { SESI } \\
\text { TERAPI }\end{array}$} & T1 & \\
\cline { 2 - 3 } & T2 & \\
\cline { 2 - 3 } & T3 & \\
\cline { 2 - 3 } & T4 & \\
\cline { 2 - 3 } & T5 & \\
\cline { 2 - 3 } & T6 & \\
\hline
\end{tabular}

Kefungsian Komunikasi Optimum tercapai apabila tahap keterukan pesakit berada pada tahap RINGAN (MILD)

Mencapai Kefungsian Komunikasi Optimum

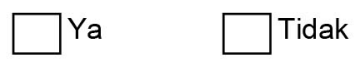

Dilaksanakan oleh 
Appendix 2: Adapted version of WAB-R in Bahasa Malaysia

Name:

D.O.B:

Gender:

Age:

Date of session:

Ethnic:

\section{SPONTANEOUS SPEECH}

\section{A. Conversational Questions}

\begin{tabular}{|c|c|c|c|}
\hline Item & Respon & Betul & Salah \\
\hline 1. Apa khabar puan? / Puan sihat ke hari ini? & & & \\
\hline 2. Pernahkah Puan datang ke sini sebelum ni? & & & \\
\hline 3. Apakah nama pertama dan nama terakhir Puan? & & & \\
\hline 4. Apakah alamat penuh rumah Puan? & & & \\
\hline 5. Apakah pekerjaan Puan? & & & \\
\hline $\begin{array}{l}\text { 6. Kenapa Puan di sini (dalam hospital)? Apa yang } \\
\text { membimbangkan Puan? }\end{array}$ & & & \\
\hline
\end{tabular}

\section{B. Huraikan Gambar}

Arahan: Ceritakan apa yang berlaku dalam gambar ini?

Prompt: Cuba puan bagitahu dalam bentuk ayat. 
Special Communications | Neurological examination of speech in Bahasa Malaysia

\section{PEMAHAMAN PERTUTURAN AUDITORI}

\section{A. Yes/No Questions}

\begin{tabular}{lll}
\multicolumn{1}{c}{ Item } & Target \\
respon & $\begin{array}{c}\text { Jenis respon (verbal, } \\
\text { gesture, eye blink, no } \\
\text { respon) }\end{array}$ & $\begin{array}{c}\text { Skor: } \\
\text { Betul- } 2 \\
\text { Salah- }\end{array}$ \\
1. Nama puan Fatimah ke? & Tidak \\
2. Nama puan Joyah ke? & Tidak \\
3. Nama puan Rakiah ke? & Ya \\
4. Puan tinggal di__? & Tidak \\
5. Puan tinggal di__? & Ya \\
6. Puan tinggal di__? & Tidak \\
7. Adakah Puan perempuan? & Ya \\
8. Adakah Puan seorang doctor? & Tidak \\
9. Saya perempuan betul? & Ya \\
10. Adakah lampu dalam bilik ni dibuka? & Ya \\
11. Adakah pintu ditutup? & Ya \\
12. Sini ialah hotel betul? & Tidak \\
13. Sini ialah hospital ke? & Ya \\
14. Puan pakai baju warna __ betul? & Tidak \\
15. Adakah kertas terbakar dalam api & Ya \\
16. Bulan March datang sebelum bulan Jun? & Ya \\
17. Puan makan pisang sebelum membuang kulitnya ke? & Tidak \\
18. Hari Kemerdekaan pada bulan Julai ke? & Tidak \\
19. Adakah kuda lebih besar daripada kambing? & Ya \\
20. Encik potong rumput menggunakan kapak ke? & Tidak \\
\end{tabular}

\section{B. Pengenalan Perkataan Auditori}

\begin{tabular}{lllll} 
Object sebenar & Object bergambar & Bentuk & Huruf & Nombor \\
1. Cawan & 7. Mancis & 13. Segi empat & 19. J & 5 \\
2. Lilin & 8. Cawan & 14. Segi tiga & 20. F & 61 \\
3. Pensel & 9. Sikat & 15. Bulat & 21. B & 500 \\
4. Bunga & 10. Pemutar skru & 16. Anak panah & 22. K & 1867 \\
5. Sikat & 11. Pensel & 17. Pangkah & 23. M & 32 \\
6. Pemutar skru & 12. Bunga & 18. Silinder & 24. D & 5000 \\
\hline
\end{tabular}




\begin{tabular}{lllll} 
Warna & Perabot & Anggota badan & Jari & Kiri- kanan \\
Biru & Tingkap & Telinga & Ibu jari & Bahu kanan \\
Perang/ coklat & Kerusi & Hidung & Jari telunjuk & Lutut kiri \\
Merah & Meja & Mata & Jari hantu & Mata kiri \\
Hijau & Lampu & Dada & Jari manis & Pergelangan tangan kanan \\
Kuning & Pintu & Leher & Jari Kelingking & Siku kiri \\
Hitam & Siling & Dagu & Telinga kanan & Pipi kanan \\
\hline
\end{tabular}

\section{Arahan Berturutan}

\section{Item}

1. Angkat tangan

2. Tutup mata

3. Tunjukkan kerusi

4. Tunjuk tingkap, lepas tu tunjuk pintu

5. Tunjuk pen dan buku

6. Tunjuk buku dengan menggunakan pen

7. Tunjuk pen dengan menggunakan buku

8. Tunjuk sikat dengan menggunakan pen.

9. Tunjuk sikat dengan menggunakan buku

10. Letak pen atas buku dan bagi saya.

11. Letak sikat di tepi pen dan terbalikkan buku.

\section{PENGULANGAN}

\section{Puan ulang balik apa yang I cakap.}

Item
1. kad
2. bas
3. paip
4. tingkap
5. pisang
6. keretapi
7. empat puluh lima
8. Sembilan puluh lima peratus
9. enam puluh dua dan setengah
10. pemasak rendang berasa gembira
11. telefon sedang berdering
12. Dia tidak akan balik
13. Roti bakar segar dan sedap
14. tiada kalau, dan atau tetapi
15. Bekas saya dipenuhi dengan lima belas botol air mineral.


Special Communications | Neurological examination of speech in Bahasa Malaysia

PENAMAAN DAN PENCARIAN PERKATAAN

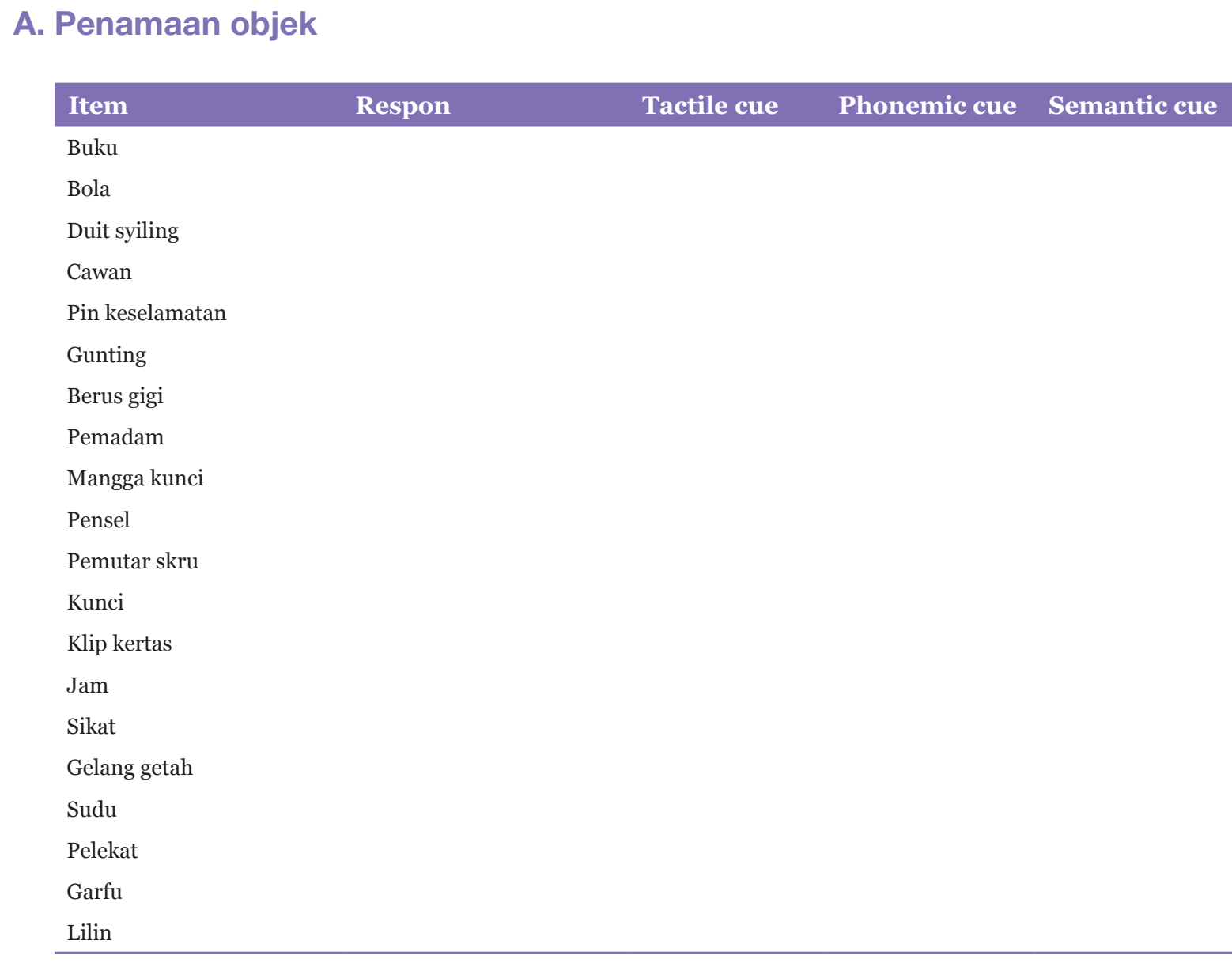

\section{B. Word Fluency}

Berikan nama haiwan sebanyak yang boleh dalam masa seminit.

\section{Sentence Completion}

\begin{tabular}{ll} 
Item & Target Respon \\
Rumput berwarna _ & hjiau \\
Gula adalah _ & Manis, putih \\
Bunga epal berwarna merah, buah pisang berwarna __ & \\
Meraka saling membantu bagai aur dengan _ & \\
Hari Kemerdekaan Malaysia ialah dalam bulan _ & \\
\hline
\end{tabular}




\section{Responsive speech}

\begin{tabular}{|c|c|c|}
\hline Item & Target respon & Respon lain \\
\hline Kita tulis guna apa? & Pen/ pensel & \\
\hline Warna duan ialah apa? & Hijau & \\
\hline Satu minggu ada berapa hari? & Tujuh & \\
\hline Di manakah jururawat bekerja? & Hospital & \\
\hline Di manakah kita boleh dapat setem? & Post office/pejabat pos & \\
\hline
\end{tabular}

\section{Oral Motor Examination}

\begin{tabular}{|c|c|c|}
\hline Structure and innervation & Tested by & Observation \\
\hline Facial : CN 7 & $\begin{array}{l}\text { - symmetry } \\
\text { - close eyes } \\
\text {-wrinkle brow }\end{array}$ & \\
\hline Lips: $\mathrm{CN} 7$ & $\begin{array}{l}\text { - smile } \\
\text { - kiss } \\
\text {-puff cheek } \\
\text { - Resist force to open lip }\end{array}$ & \\
\hline Jaw: $\mathrm{CN}_{5}$ & $\begin{array}{l}\text { - Jaw open to resistance } \\
\text {-Jaw lateralization }\end{array}$ & \\
\hline $\begin{array}{l}\text { Tongue: } \mathrm{CN} 12 \\
\text { (Strength, speed, accuracy, range of } \\
\text { motion, tone and stability) }\end{array}$ & $\begin{array}{l}\text {-Lingual movement to superior, lateral, inferior } \\
\text {-Resistance to tongue depressor anteriorly } \\
\text {-Resistance to force laterally at cheeks }\end{array}$ & \\
\hline Velum: CN 9 \& 10 & $\begin{array}{l}\text { - Symmetrical upward movement } \\
\text { - Gag reflex }\end{array}$ & \\
\hline Larynx: CN 10 & $\begin{array}{l}\text {-Volitional cough } \\
\text {-Vocal quality }\end{array}$ & \\
\hline
\end{tabular}

\section{Diadochokinetic}

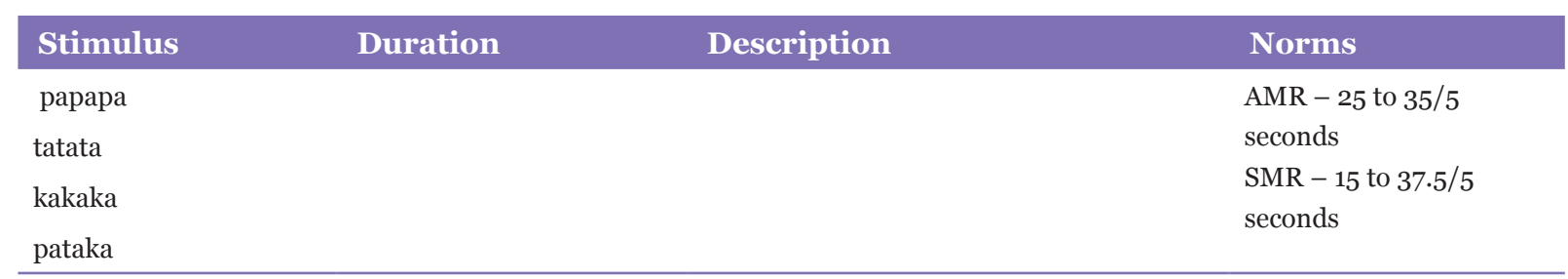


Special Communications | Neurological examination of speech in Bahasa Malaysia

\section{READING}

\section{A. Reading Comprehension Of Sentences}

Tunjukkan ayat (satu ayat per kad). Arahkan pesakit untuk baca ayat dan tunjuk kepada perkataan yang hilang. Sewaktu memberi arahan kepada pesakit, sertakan isyarat dan tunjuk kepada perkataan yang hilang dan pilihan jawapan. Ulang arahan jika pesakit tidak faham. Suruh pesakit jawab contoh soalan dahulu. Jika pesakit tunjuk kepada jawapan yang salah, bantunya dengan tunjuk kepada jawapan yang betul dan kata 'tengok, ini perkataan yang hilang'

1. Hujan

- $\quad$ Biru

- Basah

- Pasar

- $\quad$ Laut

2. Askar bawa

- Senjata

- Tembak

- Permata

- Barang runcit

3. Encik Samad membaiki kereta dan lori. Dia adalah

- $\quad$ Tukang jahit

- Mesin

- Mekanik

- Bas

4. Cikgu kembali ke sekolah selepas habis musim cuti. Cikgu mengajar

- Daun

- Kanak-kanak

- Tengkujuh

- Buku

5. Penyodok dan gergaji adalah alatan dari kumpulan yang sama. Ia mempunyai bahagian yang diperbuat dari

- Petani

- Hutan

- $\quad$ Besi

- $\quad$ Potong 
6. Petani menghasilkan tepung, jagung dan lain-lain. Petani juga menghasilkan

- Arang

- Traktor

- Bumi

- Sayur

7. Kita mempunyai tenaga yang banyak pada satu masa dahulu. Akibat kekurangan minyak, banyak negara telah beralih kepada sumber alternative seperti

- Air mendidih

- Sungai

- Matahari

- Ekonomi

8. Titanic adalah sebuah kapal laut yang dianggap tidak akan tenggelam tetapi ia merempuh aisberg dan tenggelam pada tahun 1912, membunuh hampir beribu orang. Ia tidak akan tenggelam jika tidak

- Hilang kuasa

- Rosak teruk

- Membawa penumpang

- Pergi ke barat

\section{B. Reading Commands}

Tunjukkan setiap kad dan beri arahan 'saya nak Encik baca kuat-kuat dan ikut apa yang diarahkan'. Ulang arahan jika pesakit hanya buat salah satu tugas.
1. Angkat tangan
2. Lambai 'bye'
3. Tutup mata
4. Lukis pangkah menggunakan kaki
5. Tunjuk kepada kerusi, dan kepada pintu
6. Ambil pensil, ketuk tiga kali dan letak semula

\section{Written Word Stimulus - Object Choice Matching}

Letak objek secara rawak. Arah pesakit untuk tunjuk kepada objek yang dibaca dalam perkataan di kad 22-27.
1. Cawan
2. Sikat
3. Pensil 
Special Communications | Neurological examination of speech in Bahasa Malaysia
4. Bunga
5. Mancis
6. Pemutar skru

\section{Written Word Stimulus - Object Choice Matching}

Letak kad 2 yang mempunyai gambar. Arah pesakit untuk tunjuk kepada gambar yang berpasang dengan perkataan yang diletak. Perkataan diletak berasingan pada kad 22-27.
1. Bunga
2. Mancis
3. Cawan
4. Pemutar skru
5. Sikat
6. Pensil

\section{E. Picture Stimulus - Written Word Choice Matching}

Letakkan Kad 34 mempunyai senarai perkataan. Arah pesakit untuk tunjuk kepada perkataan yang sama dengan gambar. Gambar diletak berasingan pada kad 28-33.
1. Cawan
2. Pensil
3. Pemutar skru
4. Mancis
5. Bunga
6. Sikat

\section{F. Spoken Words - Written Word Choice Matching}

Letak kad 35-38 dan suruh pesakit pilih perkataan dari 5 pilihan jawapan yang disebut oleh SC. Contohnya 'tunjukkan saya perkataan bunga'
1. Kakak pekak pokok gagak perak
2. Cincin licin makin patin miskin
3. Seluar keluar jadual peluang beruang
4. Conteng ponteng ranting canting gunting 


\section{G. Letter Discrimination}

Gunakan markah yang diperoleh pada 'letter identification' di 'auditory word recognition' subtest. Jika markah adalah 3 atau kurang, guna 'letter matching task' dengan meletakkan setiap huruf J, F, B, K, M, D dan arah pesakit untuk tunjuk kepada pilihan huruf di kad 4.

\section{H. Spelled Word Recognition}

Arah pesakit untuk namakan perkataan yang dieja oleh SC. Jika pesakit tidak faham arahan, beri contoh yang tiada dalam senarai ujian.

$$
\begin{aligned}
& \text { Y-a } \\
& \text { d-a-m } \\
& \text { k-a-r-i } \\
& \text { s-e-l-u-a-r } \\
& \text { k-e-r-t-a-s } \\
& \text { t-e-l-e-f-o-n }
\end{aligned}
$$

\section{Spelling}

Arah pesakit untuk eja perkataan berikut (disebut oleh SC). Beri contoh "dam, d-a-m" jika pesakit tidak faham arahan.

$\mathrm{Di}$

Jam

Kaki

Rumah

Pensil

Kerjasama

\section{WRITING}

\section{A. Writing on Request}

Menyuruh pesakit untuk menulis nama dan alamat rumahnya sendiri.

\section{B. Written Output}

Tunjukkan gambar (Card 1). Arahkan pesakit untuk menulis cerita tentang apa yang berlaku dalam gambar tersebut. Berikan masa 3 minit dan galakkan pesakit untuk tulis dalam ayat sekiranya pesakit tulis dalam perkataan. 
Special Communications | Neurological examination of speech in Bahasa Malaysia

\section{Writing to Dictation}

Arahkan pesakit untuk menulis ayat yang terapis sebut "Bungkuskan kotak saya dengan mengisikan 5 jug air kordial”

\section{Hentikan penilaian sekiranya pesakit mendapat markah 40 atau lebih di A, B dan C. WRITING OF DICTATED OR VISUALLY PRESENTED WORDS}

Arahkan pesakit untuk tulis perkataan yang anda sebut. Sekiranya pesakit tidak faham, tunjukkan objek sebenar dan beri gerakan (gestures) supaya pesakit menulis nama objek tersebut. Jika pesakit masih gagal, terapis eja perkataan tersebut. Jika masih gagal, suruh pesakit isikan tempat kosong dengan memberikan dua abjad contoh bola “_o_a”

\begin{tabular}{lll} 
Markah penuh sekiranya & $\begin{array}{l}\text { Markah 1/2 sekiranya dengan } \\
\text { berjaya menulis terus atau } \\
\text { dgn bantuan objek }\end{array}$ & $\begin{array}{l}\text { bantuan ejaan atau isikan } \\
\text { tempat kosong }\end{array}$ \\
Cawan & \\
Jam & \\
Telefon & \\
Pemutar skru & \\
\hline
\end{tabular}

\section{A. Alphabet and Numbers}

Arahkan pesakit untuk menulis abjad (A-Z) dan nombor (O-20).

\section{B. Dictated Letters and Numbers}

Arahkan pesakit untuk menulis abjad dan nombor yang disebut oleh terapis.

1) D, M, J, B, F

2) $5,61,32,700,1867$

\section{Copying of Words of a Sentence}

Tunjukkan kad nombor 39 dan suruh pesakit tulis semula.

\section{APRAXIA}

Beritahu pesakit “ Saya akan suruh anda untuk melakukan beberapa perkara, cuba dan lakukan sebaik mungkin”. Jika pesakit gagal untuk mengikuti arahan dengan baik, tunjukkan cara (imitate the action). Jika masih gagal, berikan objek sebenar (where applicable)*. 


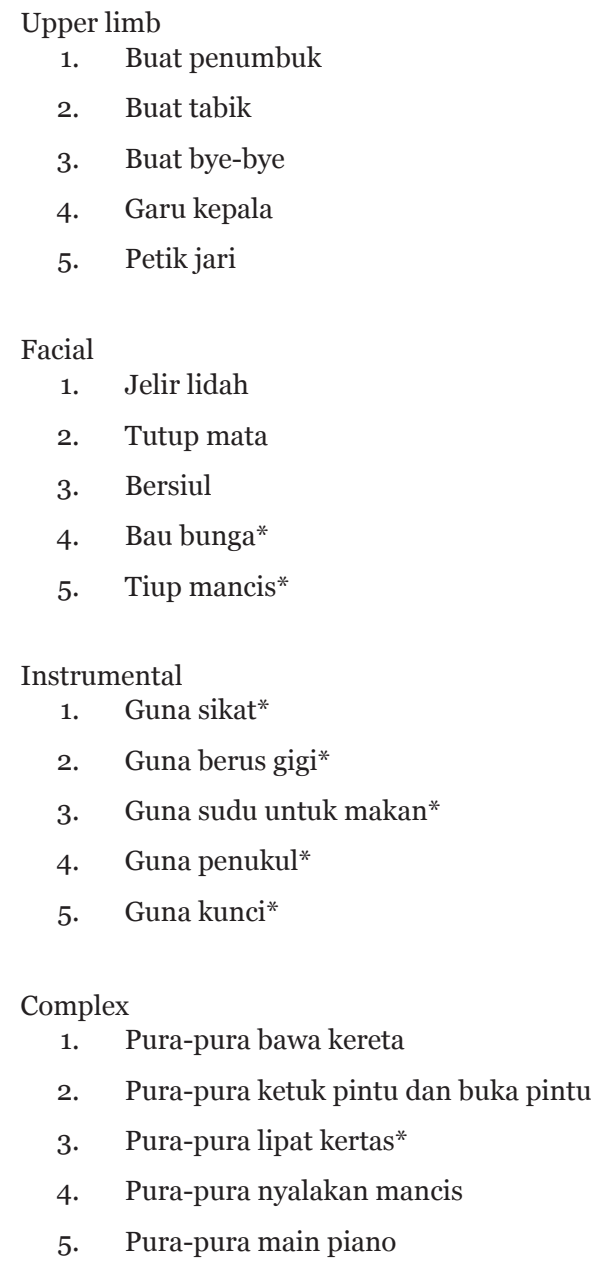

\section{READING COMPREHENSION OF SENTENCES}

Tunjukkan ayat (satu ayat per kad). Arahkan pesakit untuk baca ayat dan tunjuk kepada perkataan yang hilang. Sewaktu memberi arahan kepada pesakit, sertakan isyarat dan tunjuk kepada perkataan yang hilang dan pilihan jawapan. Ulang arahan jika pesakit tidak faham. Suruh pesakit jawab contoh soalan dahulu. Jika pesakit tunjuk kepada jawapan yang salah, bantunya dengan tunjuk kepada jawapan yang betul dan kata 'tengok, ini perkataan yang hilang'

1. Hujan

$$
\begin{array}{ll}
\text { - } & \text { Biru } \\
\text { - } & \text { Basah } \\
\text { - } & \text { Pasar } \\
\text { - } & \text { Laut }
\end{array}
$$


Special Communications | Neurological examination of speech in Bahasa Malaysia

2. Askar bawa

- Senjata

- Tembak

- Permata

- Barang runcit

3. Encik Samad membaiki kereta dan lori. Dia adalah

- $\quad$ Tukang jahit

- Mesin

- Mekanik

- Bas

4. Cikgu kembali ke sekolah selepas habis musim cuti. Cikgu mengajar

- Daun

- Kanak-kanak

- Tengkujuh

- Buku

5. Penyodok dan gergaji adalah alatan dari kumpulan yang sama. Ia mempunyai bahagian yang diperbuat dari

- Petani

- Hutan

- $\quad$ Besi

- $\quad$ Potong

6. Petani menghasilkan tepung, jagung dan lain-lain. Petani juga menghasilkan

- $\quad$ Arang

- Traktor

- Bumi

- Sayur

7. Kita mempunyai tenaga yang banyak pada satu masa dahulu. Akibat kekurangan minyak, banyak negara telah beralih kepada sumber alternative seperti

- $\quad$ Air mendidih

- Sungai

- Matahari

- Ekonomi

8. Titanic adalah sebuah kapal laut yang dianggap tidak akan tenggelam tetapi ia merempuh aisberg dan tenggelam pada tahun 1912, membunuh hampir beribu orang. Ia tidak akan tenggelam jika tidak

- Hilang kuasa

- Rosak teruk

- Membawa penumpang

- $\quad$ Pergi ke barat 


\section{Angkat tangan}

\section{Lambai 'bye'}

\section{Tutup mata}

\section{Lukis pangkah menggunakan kaki}


Special Communications | Neurological examination of speech in Bahasa Malaysia

\title{
Tunjuk kepada kerusi, dan kepada pintu
}

\section{Ambil pensil, ketuk tiga kali dan letak semula}

\author{
Cawan
}

Sikat

Pensil 


\title{
Bunga
}

Mancis

Pemutar skru

\author{
Cawan
}

Pensil

\section{Pemutar skru}


Special Communications | Neurological examination of speech in Bahasa Malaysia

\title{
Mancis
}

\section{Bunga}

\author{
Sikat
}

\author{
Kakak
}

\author{
Pekak
}

\author{
Pokok
}




\title{
Gagak
}

\author{
Perak
}

Cincin

\author{
Licin
}

Makin

\author{
Patin
}


Special Communications | Neurological examination of speech in Bahasa Malaysia

\title{
Miskin
}

\author{
Seluar
}

\author{
Keluar
}

\author{
Jadual
}

\section{Peluang}

\section{Beruang}




\title{
Conteng
}

\section{Ponteng}

Ranting

\author{
Canting
}

Gunting

\section{Bekas saya dipenuhi dengan lima belas botol air mineral.}

